Proceedings of the International Symposium on Physics of Materials (ISPMA 14), September 10-15, 2017, Prague

\title{
Fabrication of High Strength Hybrid Materials through the Application of High-Pressure Torsion
}

\begin{abstract}
M. KAWASAKI ${ }^{a}$ AND T.G. LANGDON ${ }^{b, *}$
${ }^{a}$ School of Mechanical, Industrial \& Manufacturing Engineering, Oregon State University, Corvallis, OR 97331-6001, U.S.A.

${ }^{b}$ Materials Research Group, Faculty of Engineering and the Environment, University of Southampton, Southampton SO17 1BJ, U.K.

It is well established that bulk nanostructured materials with ultrafine grains can be fabricated through the application of severe plastic deformation (SPD) since this is a promising technique for achieving significant grain refinement in bulk metals. Among the various potential SPD techniques, the most attractive appears to be processing by high-pressure torsion (HPT) because this leads to exceptional grain refinement and to grain sizes that are generally not achieved using other SPD procedures. This report describes very recent attempts to form metal matrix nanocomposites (MMNCs) by processing two dissimilar commercial metals, such as aluminum and magnesium alloys, through the use of HPT at room temperature. After significant evolutions in microstructure during the HPT processing, it is demonstrated that hybrid systems may be successfully fabricated having unique microstructures in the form of multi-layered structures. The evolution of small-scale mechanical properties was examined through the novel technique of nanoindentation and the improvement in plasticity was directly estimated by calculating the strain rate sensitivity after processing by HPT. These results demonstrate the possibility of using HPT processing for the fabrication of MMNCs having exceptional properties including very high strength.
\end{abstract}

DOI: 10.12693/APhysPolA.134.615

PACS/topics: 61.72.Mm, 62.23.St, 62.25.-g, 64.70.kd, 81.07.Bc, 81.40.Pq, 81.40.Vw

\section{Introduction}

The conventional light-weight metals including aluminum, magnesium and copper are widely used for structural applications in the automotive, aerospace and electronic industries but improvements in the mechanical properties of these metals would be attractive for enhancing their fabrication capabilities. Nevertheless, it has been established that the engineering techniques of thermomechanical processing will require additional efforts in order to achieve true nano-scale grains and thereby produce true bulk nanostructured solids. Recent investigations have established that the processing of metals through the application of severe plastic deformation (SPD) provides the potential for achieving exceptional grain refinement in bulk metal solids through the production of grains within the submicrometer and nanometer range [1].

Over the last two decades there has been a growing interest in the production of ultrafine-grained (UFG) materials including bulk nanostructured materials, where these materials are designated as interface-controlled because the grain boundaries are especially arranged by severe straining to produce superior mechanical and functional properties $[2,3]$. Experiments show that there may be a saturation in the improved mechanical properties by grain refinement when processing simple metals

*corresponding author; e-mail: langdon@soton.ac.uk and alloys. Further superior properties are not easy to obtain by processing directly on the alloy unless applying a subsequent SPD processing technique on the processed material [4]. Therefore, a new processing route is indispensable for introducing advanced materials exhibiting excellent mechanical performance and surface properties.

The objective of this report is to summarize a new approach based on utilizing conventional HPT processing [5]. The results show that it is feasible to form an Al-Mg hybrid system and ultimately obtain a metal matrix nanocomposite (MMNC) from separate $\mathrm{Al}$ and $\mathrm{Mg}$ alloy disks through diffusion bonding using HPT at room temperature (RT) under high pressure. Two earlier reports described the HPT processing at RT of disks of two different metals: specifically, half-disks of $\mathrm{Al}$ and $\mathrm{Cu}$ were placed side-by-side in an HPT facility and processed through 1, 10 and 100 turns [6] and quarter segments of $\mathrm{Cu}$ and an Al-6061 alloy were placed to form a complete disk and then processed by HPT through 1 turn [7]. In the present experiments, three disks were stacked in a vertical configuration and then processed by HPT at RT through up to 20 turns and subjected to detailed examination and micro-mechanical testing.

The present research was conducted using a commercial purity Al-1050 alloy and a ZK60 Mg alloy where these materials were selected for two reasons. First, welding and conventional bonding is difficult with $\mathrm{Mg}$ alloys because of the presence of alloying elements such as Zn. Second, a comprehensive review shows that most metals become harder and therefore stronger during HPT processing [8] but the ZK60 alloy is different because the $\mathrm{Mg}_{1} \mathrm{Zn}_{1}^{\prime}$ 
precipitates visible in the extruded alloy are fragmented in SPD processing and evolve into the $\mathrm{Mg}_{1} \mathrm{Zn}_{1}$ phase [9] leading to an overall weakening when HPT is combined with other SPD processes such as equal-channel angular pressing [10].

In practice, the experiments documented in this report demonstrate the unique microstructures, hardness distributions, micro-mechanical response and wear properties that may be attained in an Al-Mg hybrid system synthesized by HPT. A study of post-deformation annealing (PDA) was also applied to the HPT-processed disks to demonstrate an improvement in plasticity by an increase in the strain rate sensitivity, $m$

\section{Synthesis of an Al-Mg hybrid metal system through diffusion bonding}

\subsection{Hardness evolution with HPT straining}

This study used a commercial purity Al-1050 aluminum alloy and a ZK60 (Mg-4.79 wt.\% Zn-0.75 wt.\% $\mathrm{Zr})$ magnesium alloy both received in the form of extruded rods having diameters of $10 \mathrm{~mm}$. The rods were initially cut into billets with lengths of $\sim 65 \mathrm{~mm}$ and then sets of disks with uniform thicknesses of $\sim 0.83 \mathrm{~mm}$ were prepared from these billets. Separate disks of the $\mathrm{Al}$ and $\mathrm{Mg}$ alloys were then stacked in the depression on the lower anvil of the HPT facility in the order of $\mathrm{Al} / \mathrm{Mg} / \mathrm{Al}$ and each stack was set up without using any glue between the disks or any metal brushing treatment. Direct bonding of the three disks of $\mathrm{Al}$ and $\mathrm{Mg}$ was achieved through the use of conventional HPT at RT under quasiconstrained conditions in which there is a small outflow of material around the periphery of the disk during the pressing operation $[11,12]$. The processing was conducted under a hydraulic pressure of $6.0 \mathrm{GPa}$ for 1,5 , 10 and 20 turns at a rotational speed of $1 \mathrm{rpm}$.

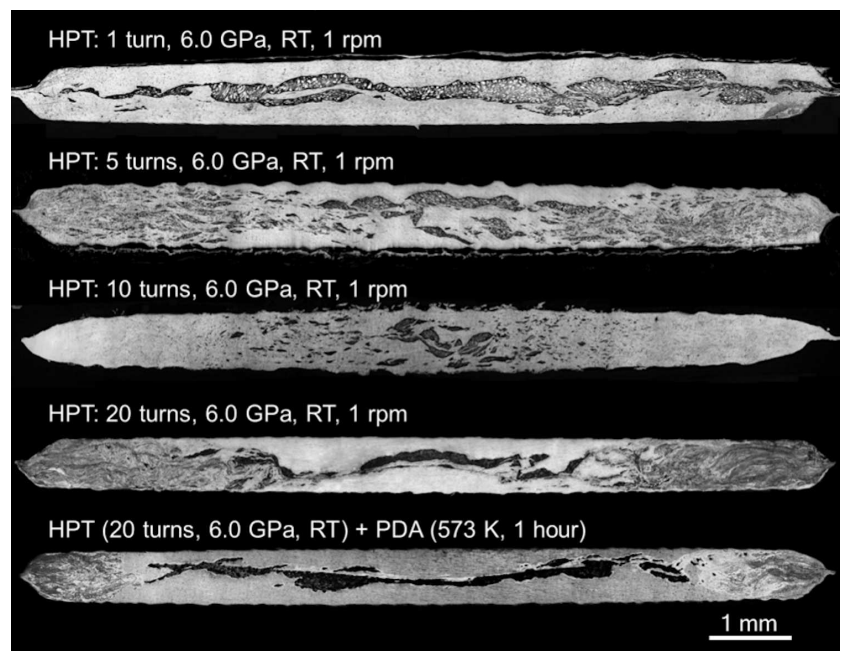

Fig. 1. The vertical cross-sections of the $\mathrm{Al}-\mathrm{Mg}$ system after HPT under a pressure of $6.0 \mathrm{GPa}$ at room temperature for, from the top, 1,5 and 10 turns [13-15] and 20 turns plus 20 turns followed by PDA [16].
Figure 1 shows overviews of the vertical cross-sections of $\mathrm{Al}-\mathrm{Mg}$ disks after HPT for, from the top, 1, 5 and 10 turns $[13-15]$ and 20 turns and then 20 HPT turns followed by post-deformation annealing (PDA) at $573 \mathrm{~K}$ for 1 hour [16]. Inspection shows that the disk after 1 turn exhibits a multi-layered phase distribution throughout the disk diameter with wavy or undulating $\mathrm{Mg}$ layers having thicknesses of $\sim 200 \mu \mathrm{m}$ without any segregation at the $\mathrm{Al}-\mathrm{Mg}$ interfaces. A similar phase distribution of multi-layered $\mathrm{Al}-\mathrm{Mg}$ is observed in the central regions of the disks at $r<2.0 \mathrm{~mm}$ after 5 turns and $r<1.0 \mathrm{~mm}$ after 10 turns of HPT where $r$ denotes the radius of the HPT disk. Thereafter, the multi-layered phase distribution seems to extend slightly towards $r \approx 3.0 \mathrm{~mm}$ after 20 HPT turns followed by PDA.

By contrast, at the disk peripheries after 5 turns there is a reasonably homogeneous distribution of very fine $\mathrm{Mg}$ phase at $r>2.5 \mathrm{~mm}$. Thus, there are small $\mathrm{Mg}$ phases with thicknesses of $\sim 5-10 \mu \mathrm{m}$ to even true nano-scale sizes of $\sim 100-500 \mathrm{~nm}$ within the Al matrix. This fine $\mathrm{Mg}$ phase disappears at the disk edges and there is no evidence of visible $\mathrm{Mg}$ phases at $\sim 3<r<5 \mathrm{~mm}$ after 10 and 20 turns. A consistent microstructural gradation involving multi-layered formation towards a complete mixture along the radial direction is observed in the $\mathrm{Al}-\mathrm{Mg}$ system after HPT for 20 turns followed by PDA and the extent of the outer region is reduced. Accordingly, the synthesized $\mathrm{Al}-\mathrm{Mg}$ system after HPT and after PDA consists of a gradient-type microstructure involving microstructural heterogeneities across the disk diameters.

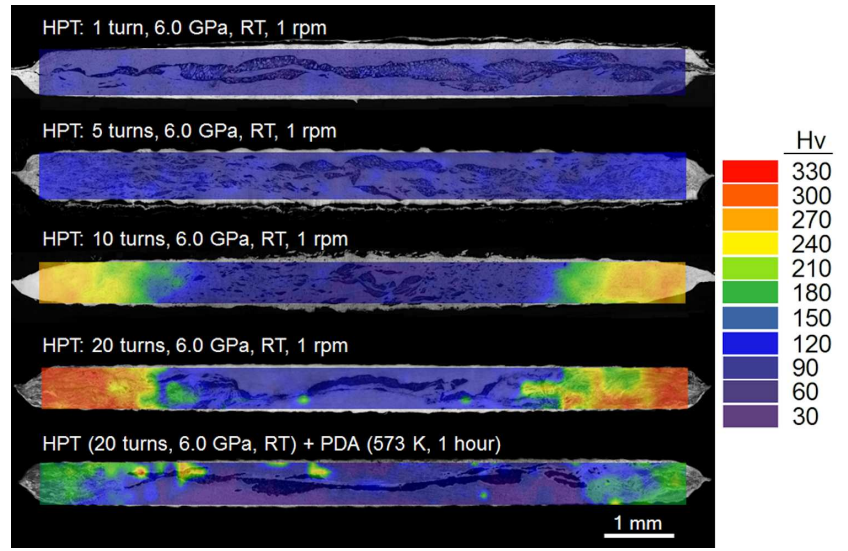

Fig. 2. Color-coded hardness contour maps taken at the vertical cross-sections along the disk diameters after HPT for 1, 5 and 10 turns $[13,14]$ and 20 turns plus 20 turns followed by PDA [16].

The distributions of hardness were examined over the vertical cross-sections for these same HPT-processed Al$\mathrm{Mg}$ disks by taking hardness measurements using a Vickers microhardness tester. The data set was visualized by constructing color-coded hardness contour maps which were then superimposed onto the optical micrographs shown in Fig. 1. The hardness contour maps constructed in this way are shown in Fig. 2 for the disks after HPT 
for, from the top, 1, 5 and 10 turns [13, 14] and for 20 turns and 20 turns followed by PDA [16], respectively; these colors indicate specific hardness values which are shown in the color key on the right. For comparison purposes, the base materials of the Al-1050 and the ZK60 alloys show a saturation hardness of $H v \approx$ 65 [17] and $H v \approx 110$ [18] across the disk diameters after HPT for 5 turns.

It is apparent from the color distributions in Fig. 2 that very high hardness is developed at the disk edges after HPT for 10 or more turns where, as shown in Fig. 1, the $\mathrm{Mg}$ phase is invisible due to the severe straining during HPT. In practice, an average microhardness value of $H v \approx 70$ was recorded at the cross-section of the $\mathrm{Al}-\mathrm{Mg}$ system after HPT for 1 turn and this is similar to the saturated hardness value of $H v \approx 65$ for the base material of the Al alloy after processing by HPT. This low value of hardness remains reasonably constant at the centres at $r<2.5-3.0 \mathrm{~mm}$ of the $\mathrm{Al}-\mathrm{Mg}$ disks up to at least 20 HPT turns.

Although the individual hardness values tend to be fairly low up to 5 HPT turns [15], there are exceptionally high values of hardness after 10 turns where a maximum hardness value of $H v \approx 270$ was recorded at the peripheral region at $r>3.0 \mathrm{~mm}[13,14]$. Furthermore, this high hardness increases even further to $H v \approx 330$ at $r>3.0 \mathrm{~mm}$ where the hardness then shows an apparent transition to $\sim 150-240$ at $r \approx 2.5-3.0 \mathrm{~mm}$ followed by $H v \approx 60-70$ at the central region at $r<2.5 \mathrm{~mm} \mathrm{[16].}$ After PDA, the HPT-processed Al-Mg disk for 20 turns exhibits a slight reduction in hardness to $H v \approx 30-50$ in the central region at $r \leq 3.0 \mathrm{~mm}$ and to $H v \approx 220$ at the peripheral region at $r \approx 4.0-5.0 \mathrm{~mm} \mathrm{[16].} \mathrm{It} \mathrm{is}$ worth noting that these very high hardness values measured at the disk peripheries after HPT are much higher than the highest achievable hardness in the base materials of the $\mathrm{Al}$ and $\mathrm{Mg}$ alloys after HPT. Therefore, it is indispensable to investigate the detailed microstructure at the region showing the high hardness in the $\mathrm{Al}-\mathrm{Mg}$ system.

\subsection{Microstructural evolution}

Detailed microstructural analyses were conducted near the disk edges at $r \approx 4.0-4.5 \mathrm{~mm}$ and the results are shown in Figs. 3 and 4 for the $\mathrm{Al}-\mathrm{Mg}$ system after HPT for 5 and 10 turns [13] plus 20 turns and HPT for 20 turns followed by PDA [16].
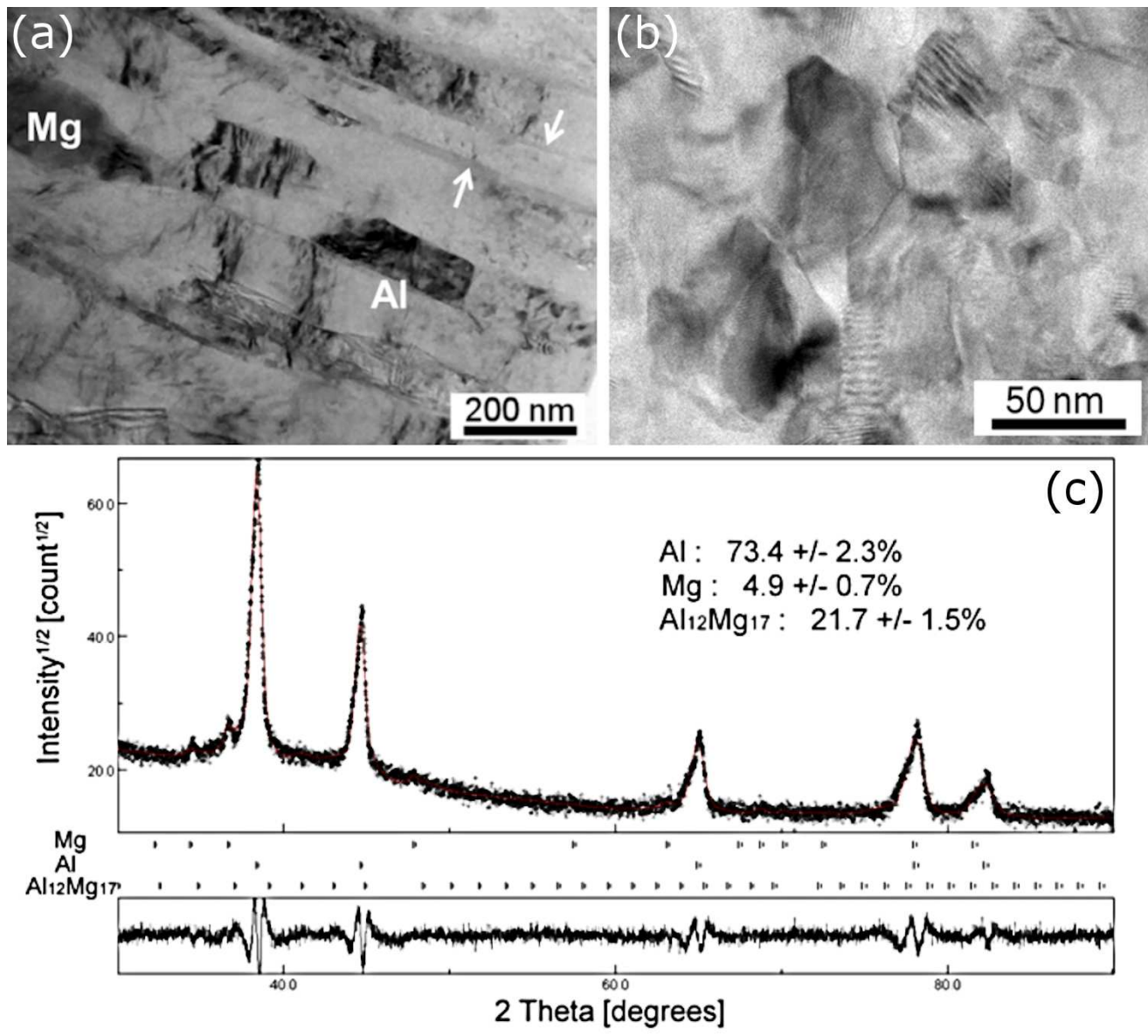

Fig. 3. TEM bright-field images taken at the $\mathrm{Al}-\mathrm{Mg}$ disk edges after HPT for (a) 5 turns and (b) 10 turns and (c) the XRD profile with the MAUD estimation for the disk edge after 10 HPT turns [13]. 

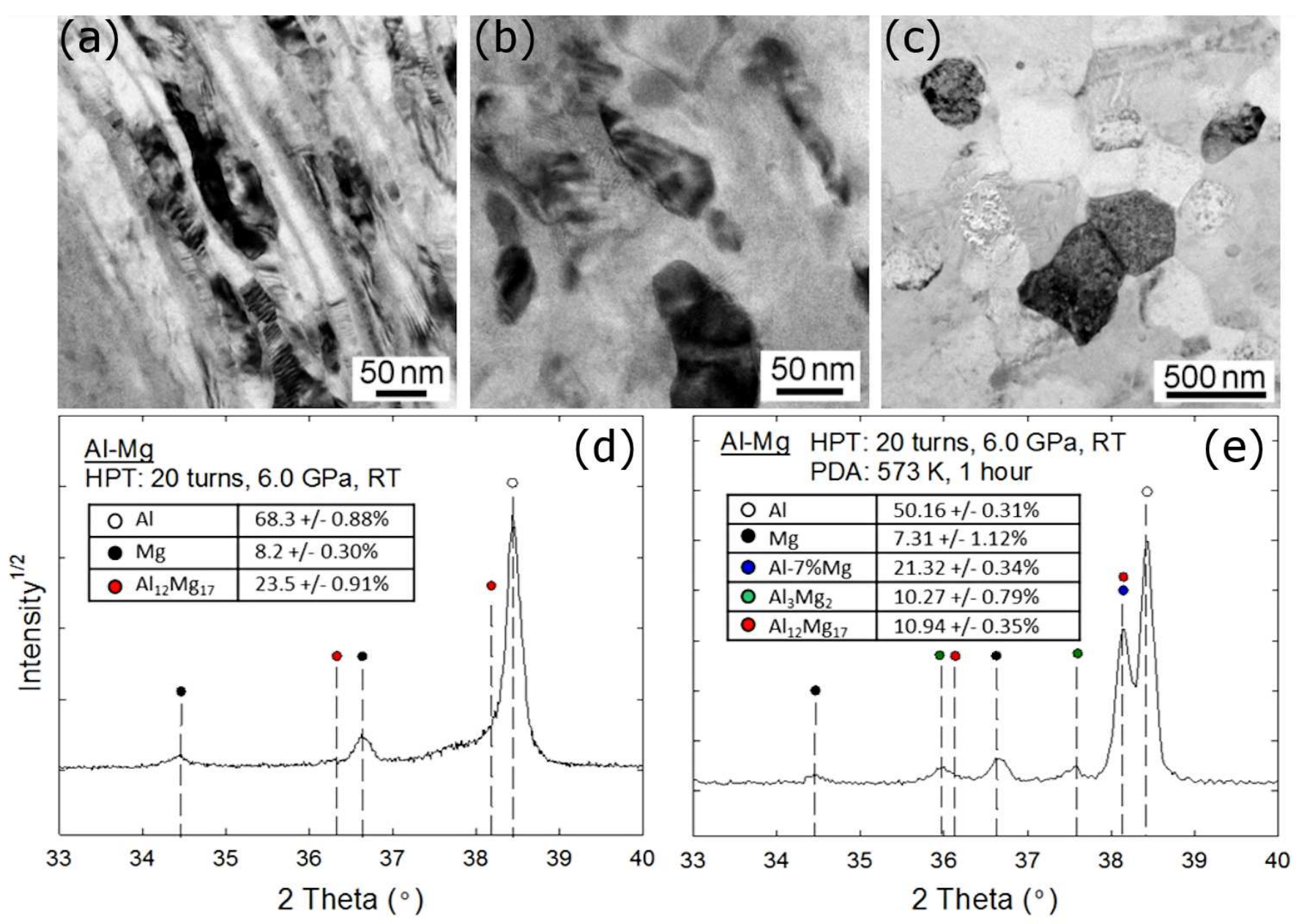

Fig. 4. Representative TEM bright-field images taken at the disk edges after (a, b) HPT for 20 turns and (c) HPT followed by PDA in the $\mathrm{Al}-\mathrm{Mg}$ system and the X-ray diffraction profiles for the disk edges of the $\mathrm{Al}-\mathrm{Mg}$ system after (d) HPT for 20 turns and (e) HPT and PDA [16].

Figure $3 \mathrm{a}$ shows the microstructure at the disk edge after 5 turns of HPT where a true nanostructure consisting of a layered microstructure was already achieved [13]. Specifically, there are layers having thicknesses of $\sim 90$ $120 \mathrm{~nm}$ and these layers contain numerous dislocations subdividing the layers in a vertical sense. In this micrograph, there is a visible $\mathrm{Mg}$ phase which has a rigid bonding interface with the $\mathrm{Al}$ matrix without the appearance of any voids. In addition, several thin nano-layers are observed within the Al matrix phase with average thicknesses of $\sim 20 \mathrm{~nm}$ as indicated by the white arrows. After 10 HPT turns in Fig. 3b, the microstructure is even finer with an average grain size of $\sim 90 \mathrm{~nm}$ and without any evidence for a Mg-rich phase. Although Fig. 3b for the disk edge after 10 turns fails to show all possible details, extensive examination showed evidence for similar type of thin layers as shown in Fig. 3a for the disk edge after 5 turns.

The disk edge after 10 HPT turns was carefully examined by removing the disk centre and using X-ray diffraction (XRD) where the profile is shown in Fig. 3c [13]. The XRD profile was then examined by MAUD [19] so that the analysis quantified the inclusion of $73.4 \pm 2.3 \%$ of $\mathrm{Al}, 4.9 \pm 0.7 \%$ of $\mathrm{Mg}$ and $21.7 \pm 1.5 \%$ of the intermetallic compound $\gamma-\mathrm{Al}_{12} \mathrm{Mg}_{17}$. It should be noted that the XRD analysis failed to detect the presence of a $\beta$ $\mathrm{Al}_{3} \mathrm{Mg}_{2}$ intermetallic compound. Despite this failure, a detailed chemical analysis at the disk edges after 5 and 10 turns revealed the presence of thin layers composed of the intermetallic compound of $\beta-\mathrm{Al}_{3} \mathrm{Mg}_{2}$ but in practice the total volume fractions of these compounds were under the XRD detectable limit [15]. Thus, the results show that HPT processing for 5-10 turns at RT leads to the synthesis of an intermetallic-based MMNC at the disk edges of the $\mathrm{Al}-\mathrm{Mg}$ system.

Figures $4 \mathrm{a}$ and $\mathrm{b}$ are representative transmission electron microscopy images taken at the peripheral region after HPT for 20 turns where it is apparent that there is a mixture of microstructures with nanolayered structures and equiaxed grain structures, respectively [16]. In practice, the nanolayered microstructure with an average thickness of $\sim 20 \mathrm{~nm}$ contains numerous dislocations lying in a vertical sense and the equiaxed microstructure shows an average grain size of $\sim 60 \mathrm{~nm}$. By contrast, 
a homogeneous equiaxed microstructure was observed in the Al-Mg system after HPT for 20 turns followed by a PDA treatment where there is an apparent microstructural recovery as shown in Fig. 4c [16]. These equiaxed grains in Fig. 4c give an average grain size of $\sim 380 \mathrm{~nm}$.

The corresponding X-ray profiles are shown in Figs. 4d and $\mathrm{e}$ for the $\mathrm{Al}-\mathrm{Mg}$ disk edges after 20 HPT turns and after HPT followed by PDA, respectively, and additional compositional analysis through MAUD is displayed as a separate listing in each plot [16]. It is important to note that these disk edges after HPT for 20 turns do not include any $\mathrm{Mg}$-rich phases whereas inevitable concentrations of $\mathrm{Mg}$-rich phases exist close to the mid-radius of the processed samples.

It is apparent from the results through MAUD that the disk edge immediately after HPT for 20 turns shows evidence for $\gamma-\mathrm{Al}_{12} \mathrm{Mg}_{17}$ in the $\mathrm{Al}$ matrix whereas after PDA there is an $\mathrm{Al}-7 \% \mathrm{Mg}$ solid solution phase with two different intermetallic compounds of $\beta-\mathrm{Al}_{3} \mathrm{Mg}_{2}$ and $\gamma$ $\mathrm{Al}_{12} \mathrm{Mg}_{17}$. Thus, these results demonstrate that HPT processing through 20 turns and HPT plus an additional PDA procedure synthesizes two different types of deformation-induced MMNCs containing intermetallic compounds at the disk edges of the $\mathrm{Al}-\mathrm{Mg}$ alloy system. Furthermore, the experimental results suggest a significant potential for improving the hardness and strength at the disk edges of the Al-Mg system through the formation of these intermetallic compounds.

\subsection{Micro-mechanical properties}

The novel technique of nanoindentation was used to examine the micro-mechanical response of the $\mathrm{Al}-\mathrm{Mg}$ system processed by HPT and after HPT with subsequent PDA. Figure 5 shows representative load-displacement $(P-h)$ curves measured at an equivalent strain rate of $1.0 \times 10^{-3} \mathrm{~s}^{-1}$ at the specific phases of (a) $\mathrm{Al}$ and (b) $\mathrm{Mg}$ at the disk centre and (c) a mixture of $\mathrm{Al}$ and $\mathrm{Mg}$ phases and an intermetallic compound of $\beta-\mathrm{Al}_{3} \mathrm{Mg}_{2}$ at the disk edge after HPT for 5 turns [14].
The disk centre with the $\mathrm{Al}$ and $\mathrm{Mg}$ multi-layers shows a series of $P-h$ curves with less broadening between the fifteen separate measurements as is apparent in Figs. 5a and b, respectively. Thus, these mechanical responses are stable within the phases in the multi-layered microstructure at the disk centre. Moreover, it is apparent from Fig. 5a that higher ductility is attained in the $\mathrm{Al}$ phase with larger displacements under a fixed load by comparison with the $\mathrm{Mg}$ phase in the central region after HPT for 5 turns. This demonstrates a reasonable consistency of mechanical response in these initial base alloys.

By contrast, there is a wide deviation in the $P$ $h$ curves in Fig. $5 \mathrm{c}$ for the $\mathrm{Al}-\mathrm{Mg}$ disk edge after $5 \mathrm{HPT}$ turns thereby indicating the forming of a plastic instability at the disk edge of the MMNC. This plastic instability was observed at all indentation rates applied in these measurements although the slowest strain rate revealed a lower tendency. It should be noted that all independent measurements among the behavior of plastic instability at the disk edge showed smaller displacements than the separate $\mathrm{Al}$ and $\mathrm{Mg}$ phases without any intermetallic compound at the disk centre as shown in Figs. 5a and b. Thus, these results confirm the high hardness at the disk edge which is reinforced by an intermetallic compound and the load-displacement data are consistent with the hardness results as demonstrated pictorially in Fig. 2.

Figure 6 shows representative $P-h$ curves for the $\mathrm{Al}-\mathrm{Mg}$ disk edges after (a) HPT for 20 turns and (b) 20 HPT turns followed by PDA when measuring at four equivalent strain rates from $1.25 \times 10^{-4}$ to $1.0 \times$ $10^{-3} \mathrm{~s}^{-1}[16]$. It is apparent that there is no strain rate dependency of plasticity at the disk edge for the MMNC processed by HPT for 20 turns since the $P-h$ curves at all four strain rates are reasonably consistent. By contrast, after 20 turns and PDA the disk edge consists of an MMNC with different compositions as revealed by the apparent positive strain rate dependency in which there are increasing displacements at slower strain rates of nanoindentation as shown in Fig. 6 b.
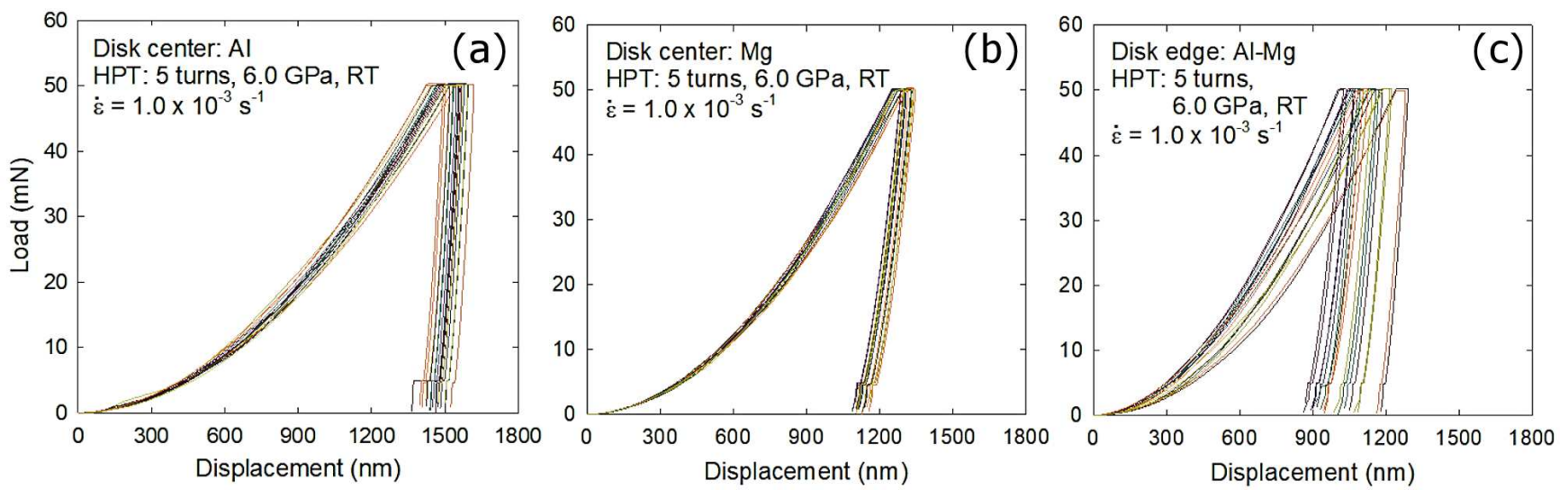

Fig. 5. Representative load-displacement curves for (a) $\mathrm{Al}$ and (b) $\mathrm{Mg}$ phases at the disk centre and for the $\mathrm{Al}-\mathrm{Mg}$ system forming an MMNC at the disk edge when testing at $1.0 \times 10^{-3} \mathrm{~s}^{-1}$ for the sample after 5 turns by HPT [14]. 

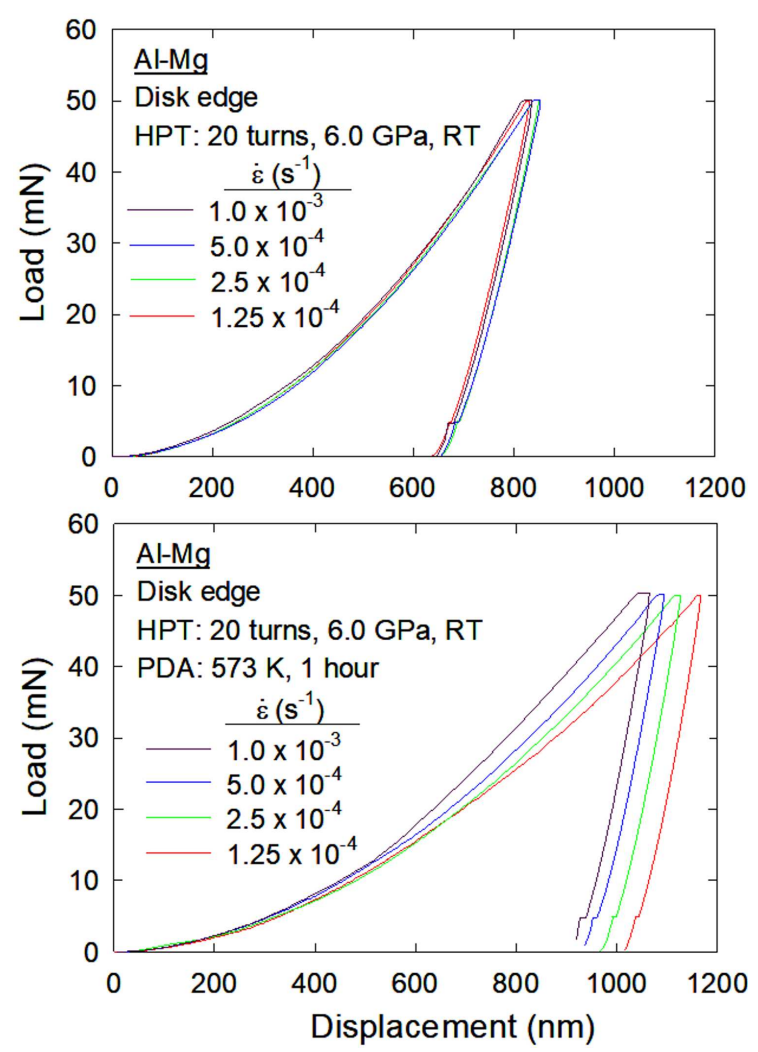

Fig. 6. Representative load-displacement curves for the $\mathrm{Al}-\mathrm{Mg}$ disk edges after (a) HPT for 20 turns and (b) HPT and PDA when measuring at four strain rates from $1.0 \times 10^{-3}$ to $1.25 \times 10^{-4} \mathrm{~s}^{-1}$ under a predetermined maximum peak load of $50 \mathrm{mN}$ [16].

Following the standard procedure of taking the flow stress equivalent to $H / 3$ for fully plastic deformation at a constant strain rate where $H$ is the nanoindentation hardness estimated from conventional indentation data [20], the value of the strain rate sensitivity, $m$, may be estimated directly from the slope of a logarithmic plot of $H / 3$ versus strain rate [21]. Using this procedure, Fig. 7a shows $H / 3$ versus strain rate for the disk edge after 5 turns giving $m<0.01$ [14, 22]. A similar plot is shown in Fig. 7b after 20 turns for samples before and after subjecting to PDA and for these samples the values of $m$ change from -0.001 after the HPT processing to $m=0.1$ after HPT and PDA [16]. The occurrence of a negative strain rate sensitivity is associated with inhomogeneous deformation and an instability in plasticity from the Portevin-Le Chatelier effect due to the occurrence of dynamic strain aging [23].

\subsection{Tribological properties}

The tribological properties were measured after HPT processing through 20 turns both without PDA and with a subsequent PDA using a tribology tester with a sliding testing mode at RT. Small-scale sliding tests were conducted in the peripheral regions of the disks under a constant load, $P$, of $3 \mathrm{~N}$ and the friction coefficients were

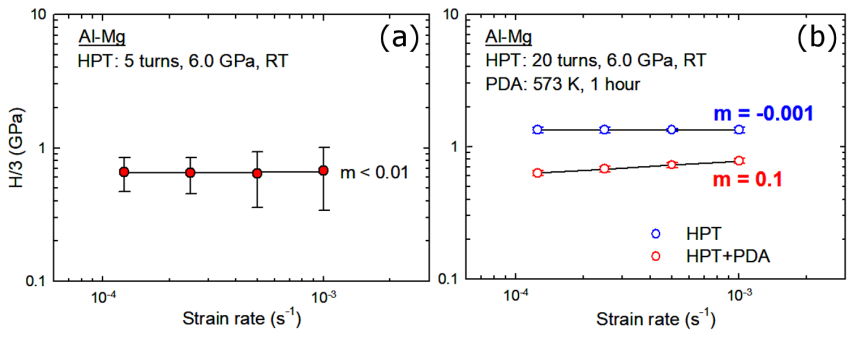

Fig. 7. Variations of the strain rate sensitivity with increasing strain rate for the disk edges of the $\mathrm{Al}-\mathrm{Mg}$ system after HPT for (a) 5 turns [14, 22] and (b) 20 turns and after HPT and PDA [16].

measured for each disk using a total sliding distance, $L$, of $20 \mathrm{~m}$. Following testing, the disks were cleaned and the weight loss of each disk was measured to determine the wear rate.

Figure 8 shows, on the left, three-dimensional depthsensing profiles recorded at the vertical sections in the middle of the wear tracks and, on the right, scanning electron microscopy images of the worn surfaces where (a) and (b) are for the disk edge after HPT for 20 turns and $(\mathrm{c})$ and $(\mathrm{d})$ are for the MMNC processed by HPT for 20 turns and then by PDA: the depth information for the vertical profiles is given in the color keys on the right of the two vertical sections [16].

Table I provides a detailed summary of the results obtained from these experiments where the top two rows record data for the MMNC after HPT for 20 turns and after HPT for 20 turns plus PDA and the bottom two rows provide comparative information for the initial Al-1050 and ZK60 alloys after processing by HPT for 10 turns. It is important to note that the MMNC densities were measured only at the disk edges and both samples, after HPT and after HPT plus PDA, gave similar densities of $\sim 2.34 \mathrm{~g} / \mathrm{cm}^{3}$. It is possible to define a normalized version of the wear coefficient, $k$, as $V / P L$ where $V$ is the wear volume [24] so that a lower value of $k$ denotes an improved wear resistance. A review of the data in Table I shows that the value of $k$ is lower after HPT for 20 turns than after HPT plus PDA and it is also significantly lower than for the separate $\mathrm{Al}$ and $\mathrm{Mg}$ alloys processed through 10 turns. This result shows that processing through HPT for 20 turns provides the potential for producing an MMNC with a very high wear resistance and this conclusion is consistent with the correlation demonstrated earlier between hardness and wear [25]. Finally, it is noted from Table I that the $k$ value is increased after HPT plus PDA but nevertheless it remains lower than in the separate $\mathrm{Al}$ and $\mathrm{Mg}$ alloys. This ability to maintain a reasonable level of wear resistance is due to the improved strain hardening capability after processing by HPT.

\subsection{Effect of HPT processing with additional disks}

Additional experiments were also conducted to determine the efficiency of metal mixing at the macroscale in the processing of the $\mathrm{Al}-\mathrm{Mg}$ system by HPT. 

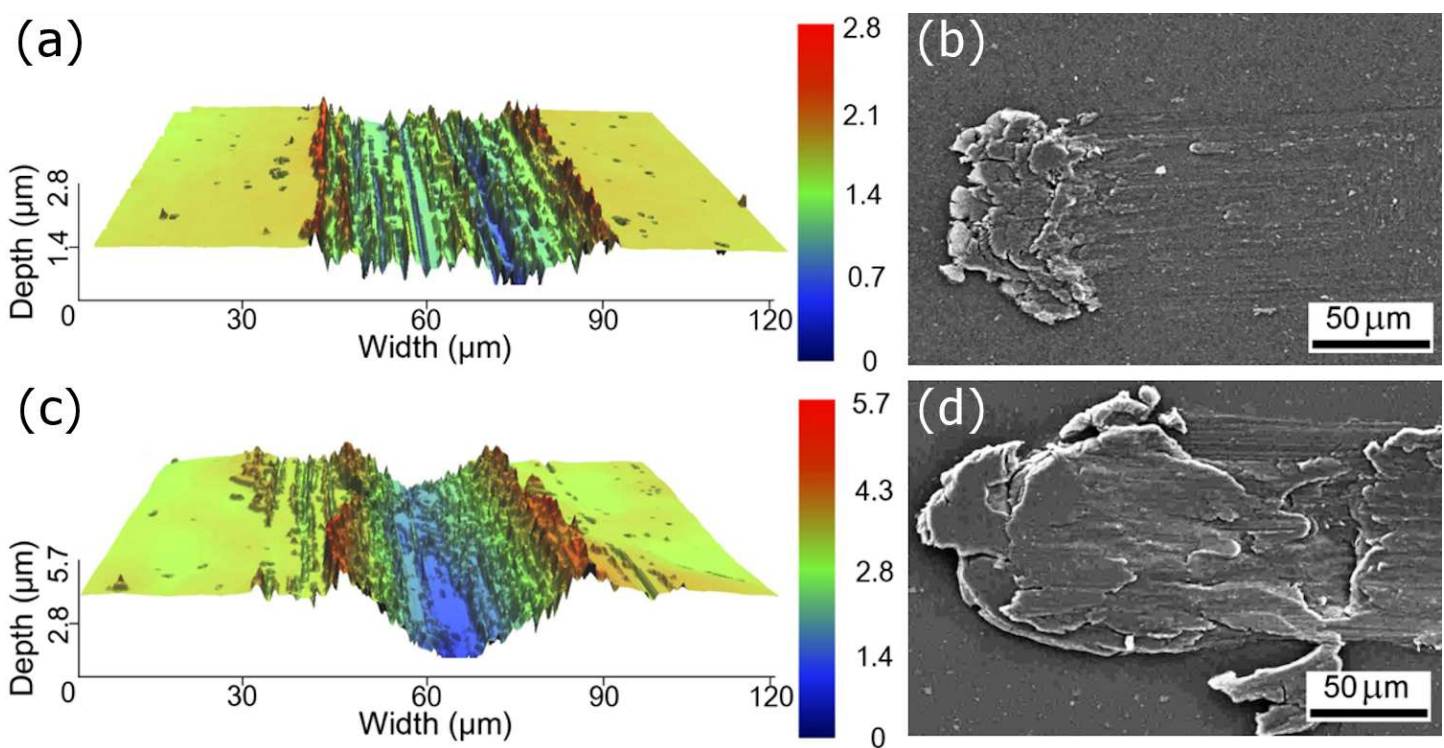

Fig. 8. Three-dimensional depth-sensing images at the vertical sections in the middle of the wear tracks (left) and the SEM micrographs of the worn surfaces (right) for (a) and (b) the MMNC at the disk edge in the Al-Mg system after HPT for 20 turns and (c) and (d) another MMNC at the disk edge after HPT and PDA: the detailed depth information is denoted by the color key beside each depth-sensing plot [16].

The measured friction coefficients, weight loss, density, wear volume and the estimated specific wear rate at $P=3 \mathrm{~N}$ and $L=20 \mathrm{~m}$ for the MMNCs in the Al-Mg system after HPT for 20 turns, after HPT and PDA and for the initial Al-1050 and ZK60 alloys after HPT for 10 turns

\begin{tabular}{|c|c|c|c|c|c|}
\hline & Friction coefficient & Weight loss [g] & Density $\left[\mathrm{g} / \mathrm{cm}^{3}\right]$ & Volume loss $\left[\mathrm{mm}^{3}\right]$ & $\begin{array}{l}\text { Specific wear } \\
\text { rate }\left[\mathrm{mm}^{3} / \mathrm{Nm}\right]\end{array}$ \\
\hline HPT: 20 turns & 0.406 & 0.00075 & 2.34 & 0.32 & 0.005 \\
\hline $\mathrm{HPT}+\mathrm{PDA}$ & 0.480 & 0.00165 & 2.34 & 0.71 & 0.012 \\
\hline Al 10 turns & 0.628 & 0.00230 & 2.73 & 0.84 & 0.014 \\
\hline Mg 10 turns & 0.306 & 0.00310 & 1.84 & 1.68 & 0.028 \\
\hline
\end{tabular}
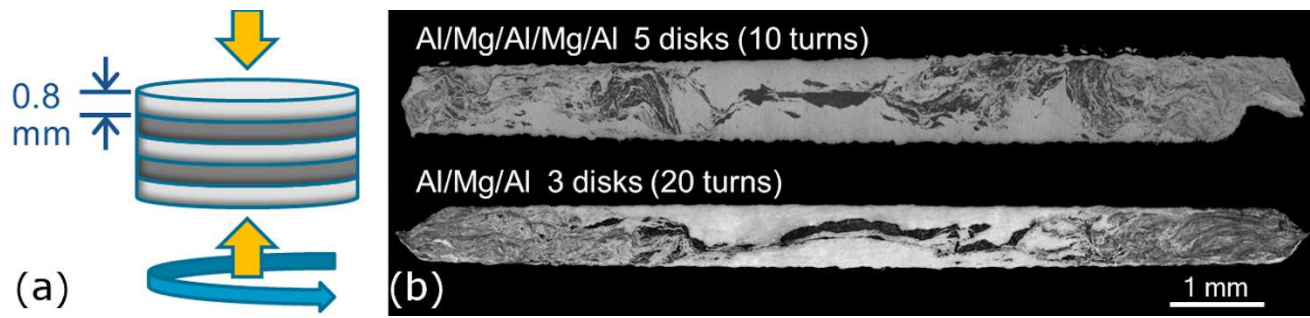

Fig. 9. (a) Schematic illustration of HPT processing for five stacked disks of two different metals and (b) microstructures taken at the cross-sections of the Al-Mg systems processed by HPT for 5 disks taken through 10 turns (upper) and 3 disks taken through 20 turns (lower) [26].

Specifically, a total of five disks of the $\mathrm{Al}$ and $\mathrm{Mg}$ samples, having the same consistent thickness of $\sim 0.8 \mathrm{~mm}$, were stacked on the lower anvil of the HPT facility in the order of $\mathrm{Al} / \mathrm{Mg} / \mathrm{Al} / \mathrm{Mg} / \mathrm{Al}$ and then processed by HPT for 10 turns under a pressure of $6.0 \mathrm{GPa}$ at RT. A schematic illustration of the specific sample set-up with five stacked disks is shown in Fig. 9a.

Figure $9 \mathrm{~b}$ shows a vertical cross-section of the HPTprocessed $\mathrm{Al}-\mathrm{Mg}$ system after 10 turns at 6.0 $\mathrm{GPa}$ from the five stacked disks (upper) and a similar result for the same $\mathrm{Al}-\mathrm{Mg}$ system from three stacked disks processed by HPT for 20 turns under the same pressure of 6.0 GPa (lower) [26]. Inspection shows that these different conditions both exhibit a similar and consistent microstructural formation where the central region after HPT has clear separations of the $\mathrm{Al}$ and $\mathrm{Mg}$ phases but this changes to a complex mixture of ultrafine $\mathrm{Al}$ and $\mathrm{Mg}$ phases towards the edges of both disks. Specifically, these microstructural changes are visible at $r \approx 2.5 \mathrm{~mm}$ in the two different conditions of HPT sample set-up. 
Therefore, it is reasonable to conclude that stacking of larger numbers of dissimilar metal disks will be effective for rapidly achieving a metal mixture, and ultimately a fast rate of diffusion, during processing by HPT. This strategy was applied recently to assemble a single bulk material from $19 \mathrm{Cu}$ foils and $18 \mathrm{Ta}$ foils stacked alternately and then processed by HPT under a pressure of 4 GPa for up to 150 turns [27].

It should be noted that, using an initial configuration as in Fig. 9a, a significant volume of material flows out from around the periphery of the disk during the quasiconstrained HPT process. Nevertheless it is clear that the mix of dissimilar metals may be accelerated by the new HPT processing route by simultaneously applying the processing to an increased number of metal disks. Thus, as seen in Fig. 9b, the final thickness of the five stacked $\mathrm{Al}-\mathrm{Mg}$ alloy was $\sim 1.0 \mathrm{~mm}$ and this is slightly larger than the thickness of $\sim 0.8 \mathrm{~mm}$ for the three stacked disks. In principle, therefore, this processing route fails to maintain a constant sample volume and this is contrary to the basic principles of processing by SPD. Nevertheless, this difference is not important and the new strategy of HPT opens up the potential for using HPT processing in the synthesizing of new types of metal systems including metal matrix nanocomposites.

\section{Summary and conclusions}

1. Processing by HPT may be used to bond disks of different metals and to achieve exceptionally high hardness and unusual strength by refining grains to the nanometer level and forming intermetallic compounds. An example is presented by stacking three disks of $\mathrm{Al} / \mathrm{Mg} / \mathrm{Al}$ alloys to produce a metal matrix nanocomposite (MMNC).

2. Nanoindentation is a useful tool for measuring the small-scale mechanical properties after HPT and after HPT plus post-deformation annealing. Using tribological testing, it is shown that an MMNC produced from $\mathrm{Al} / \mathrm{Mg} / \mathrm{Al}$ exhibits a very high wear resistance but the wear resistance is reduced to some extent by PDA.

3. The stacking of five disks instead of three is effective in rapidly achieving a metal mixture during HPT processing. This suggests that it is advantageous to simultaneously process an increased number of metal disks.

\section{Acknowledgments}

This work was supported in part by the National Science Foundation of the United States under Grant Nos DMR-1160966 and DMR-1810343 and in part by the European Research Council under ERC Grant Agreement No. 267464-SPDMETALS.

\section{References}

[1] R.Z. Valiev, R.K. Islamgaliev, I.V. Alexandrov, Prog. Mater. Sci. 45, 103 (2000).
[2] R.V. Valiev, Y. Estrin, Z. Horita, T.G. Langdon, M.J. Zehetbauer, Y.T. Zhu, JOM 58(4), 33 (2006).

[3] R.Z. Valiev, Y. Estrin, Z. Horita, T.G. Langdon, M.J. Zehetbauer, Y.T. Zhu, Mater. Res. Lett. 4, 1 (2016).

[4] S. Sabbaghianrad, T.G. Langdon, Mater. Sci. Eng. A 596, 52 (2014).

[5] A.P. Zhilyaev, T.G. Langdon, Prog. Mater. Sci. 53, 893 (2008).

[6] K. Oh-ishi, K. Edalati, H.S. Kim, K. Hono, Z. Horita, Acta Mater. 61, 3482 (2013).

[7] O. Bouaziz, H.S. Kim, Y. Estrin, Adv. Eng. Mater. 15, 336 (2013).

[8] M. Kawasaki, J. Mater. Sci. 49, 18 (2014).

[9] B. Li, S. Joshi, K. Azevedo, E. Ma, K.T. Ramesh, R.B. Figueiredo, T.G. Langdon, Mater. Sci. Eng. A 517, 24 (2009).

[10] S. Sabbaghianrad, S.A. Torbati-Sarraf, T.G. Langdon, Mater. Sci. Eng. A 712, 373 (2018).

[11] R.B. Figueiredo, P.R. Cetlin, T.G. Langdon, Mater. Sci. Eng. A 528, 8198 (2011).

[12] R.B. Figueiredo, P.H.R. Pereira, M.T.P. Aguilar, P.R. Cetlin, T.G. Langdon, Acta Mater. 60, 3190 (2012).

[13] B. Ahn, A.P. Zhilyaev, H.-J. Lee, M. Kawasaki, T.G. Langdon, Mater. Sci. Eng. A 635, 109 (2015).

[14] B. Ahn. H.-L. Lee, I.-C. Choi, M. Kawasaki, J.-I. Jang, T.G. Langdon, Adv. Eng. Mater. 18, 1001 (2016).

[15] M. Kawasaki, B. Ahn, H.-J. Lee, A.P. Zhilyaev, T.G. Langdon, J. Mater. Res. 31, 88 (2016).

[16] J.-K. Han, H.-J. Lee, J.I. Jang, M. Kawasaki, T.G. Langdon, Mater. Sci. Eng. A 684, 318 (2017).

[17] M. Kawasaki, S.N. Alhajeri, C. Xu, T.G. Langdon, Mater. Sci. Eng. A 529, 345 (2011).

[18] H.-J. Lee, S.K. Lee, K.H. Jung, G.A. Lee, B. Ahn, M. Kawasaki, T.G. Langdon, Mater. Sci. Eng. A 630 $90(2015)$.

[19] L. Lutterotti, Nucl. Instrum. Methods Phys. Res. Sect. B 268, 334 (2010).

[20] W.C. Oliver, G.M. Pharr, J. Mater. Res. 7, 1564 (1992).

[21] I.-C. Choi, Y.-J. Kim, Y.M. Wang, U. Ramamurty, J.-I. Jang, Acta Mater. 61, 7313 (2013).

[22] M. Kawasaki, B, Ahn, P. Kumar, J.I. Jang, T.G. Langdon, Adv. Eng. Mater. 19, 1600578 (2017).

[23] O. Andreau, J. Gubicza, N.X. Zhang, Y. Huang, P. Jenei, T.G. Langdon, Mater. Sci. Eng. A 615, 231 (2014).

[24] J.F. Archard, J. Appl. Phys. 24, 981 (1953).

[25] N. Gao, C.T. Wang, R.J.K. Wood, T.G. Langdon, J. Mater. Sci. 47, 4779 (2012).

[26] M. Kawasaki, J.-K. Han, D.-H. Lee, J.-i. Jang, T.G. Langdon, J. Mater. Res. 33, 2700 (2018).

[27] N. Ibrahim, M. Peterlechner, F. Emeis, M. Wegner, S.V. Divinski, G. Wilde, Mater. Sci. Eng. A 685, 19 (2017). 